\title{
Identification of molecular mechanisms for cellular drug resistance by combining drug activity and gene expression profiles
}

\author{
L Rickardson', M Fryknäs², S Dhar', H Lövborg', J Gullbo', M Rydåker², P Nygren³, MG Gustafsson ${ }^{2,4}$, \\ R Larsson*,I and A Isaksson ${ }^{2}$ \\ 'Department of Medical Sciences, Division of Clinical Pharmacology, Uppsala University Hospital, S-75I 85 Uppsala, Sweden; ${ }^{2}$ Department of Genetics \\ and Pathology, Uppsala University, S-75 I 85 Uppsala, Sweden; ${ }^{3}$ Department of Oncology, Radiology and Clinical Immunology, Uppsala University, S-75 I \\ 85 Uppsala, Sweden; ${ }^{4}$ Department of Engineering Sciences, Uppsala University, S-75I 85 Uppsala, Sweden
}

\begin{abstract}
Acquired drug resistance is a major problem in cancer treatment. To explore the genes involved in chemosensitivity and resistance, I0 human tumour cell lines, including parental cells and resistant subtypes selected for resistance against doxorubicin, melphalan, teniposide and vincristine, were profiled for mRNA expression of 7400 genes using cDNA microarray technology. The drug activity of 66 cancer agents was evaluated on the cell lines, and correlations between drug activity and gene expression were calculated and ranked. Hierarchical clustering of drugs based on their drug-gene correlations yielded clusters of drugs with similar mechanism of action. Genes correlated with drug sensitivity and resistance were imported into the PathwayAssist software to identify putative molecular pathways involved. A substantial number of both proapoptotic and antiapoptotic genes such as signal transducer and activator of transcription I, mitogen-activated protein kinase I and focal adhesion kinase were found to be associated to drug resistance, whereas genes linked to cell cycle control and proliferation, such as cell division cycle 25A and signal transducer of activator of transcription 5A, were associated to general drug sensitivity. The results indicate that combined information from drug activity and gene expression in a resistance-based cell line panel may provide new knowledge of the genes involved in anticancer drug resistance and become a useful tool in drug development.
\end{abstract}

British Journal of Cancer (2005) 93, 483-492. doi: I 0.1038/sj.bjc.6602699 www.bjcancer.com

Published online 12 July 2005

(C) 2005 Cancer Research UK

Keywords: chemotherapy; drug resistance; gene microarray

Chemotherapy is an important modality for the treatment of malignant tumours. However, for the majority of cancer patients, treatment with established anticancer drugs produces dissatisfactory long-term effects and drug activity is highly variable both between and within different diagnoses (Nygren, 2001). Genes affecting chemosensitivity are involved in drug transport, drug metabolism, DNA synthesis and repair, cell survival and apoptosis (Marie, 2001; Pommier et al, 2004). Since many different signalling pathways are involved, there is an urgent need for high-efficacy drugs with novel mechanisms of action targeting the key genes.

Rapid cell-based methods for high-throughput and focused screening based on drug-response analysis in a panel of cell lines have proven to be important tools in anticancer drug discovery and early evaluation (Paull et al, 1989; Boyd and Paull, 1995; Dhar et al, 1996; Weinstein et al, 1997). Research performed at the National Cancer Institute (NCI) has shown that a drug activity profile acquired from a nonclonogenic growth inhibition assay on a panel of 60 parental human cancer cell lines can provide important information on the mechanism of action of various compounds. Robust and accurate mechanistic drug-drug relationships have repeatedly been demonstrated using both simple correlation analysis and more sophisticated data analytical

*Correspondence: Professor R Larsson; E-mail: rolf.larsson@medsci.uu.se Received 20 January 2005; revised 25 May 2005; accepted 10 June 2005; published online 12 July 2005 methods (Paull et al, 1989; Weinstein et al, 1992, 1997; Boyd and Paull, 1995). We have previously shown that, by applying similar techniques, a smaller panel of 10 cell lines representing different drug-resistant phenotypes could accomplish accurate classifications of mechanisms of action for common anticancer drugs (Dhar et al, 1996).

The development of novel molecular technologies such as cDNA microarrays has made it possible to identify genes involved in chemosensitivity. Integration of gene expression and drug activity data sets for cancer cells can identify relationships between individual genes and sensitivity or resistance to specific drugs. Investigators at NCI analysed the gene expression profiles of the NCI human tumour cell line panel and correlated the gene expression to growth-inhibitory activity of anticancer compounds (Scherf et al, 2000).

Several genes were identified which could be considered as candidate targets or biomarkers for chemosensitivity. The approach was considered feasible and useful for exploring the mechanisms of action, and was supported by investigators applying a similar methodology on a 39-cell line panel (Dan et al, 2002). The cell lines used in these studies consisted of parental cells of different cancer types and did not include any selected resistant phenotypes. With the aim of identifying chemosensitivity genes, the inclusion of resistant cell lines may be advantageous by increasing the range of expression in the measured microarray data, specifically for the genes involved in 
development of resistance. Therefore, in the present study, a cell line panel representing different drug resistance phenotypes, rather than histological origin, was characterised with respect to gene expression and anticancer drug response, and the relationships between the resulting drug and gene expression profiles were subsequently explored. By association analyses using pathway mining software, molecular pathways putatively involved in drug resistance and sensitivity were identified.

\section{MATERIALS AND METHODS}

\section{Cell culture}

The human cancer cell line panel has been described previously (Dhar et al, 1996). The panel consists of the parental cell lines RPMI 8226 (myeloma), CCRF-CEM (leukaemia), U937-GTB (lymphoma) and NCI-H69 (small-cell lung cancer); the drugresistant sublines 8226/Dox40 8226/LR5, CEM/VM-1, U937/vcr, H69AR and the primary resistant ACHN (renal adenocarcinoma). $8226 /$ Dox 40 was exposed to $0.24 \mu \mathrm{g} \mathrm{ml}^{-1}$ of doxorubicin once a month, and overexpresses Pgp/MDRl/ABCBl (Dalton et al, 1986). $8226 / \mathrm{LR} 5$ was exposed to $1.53 \mu \mathrm{g} \mathrm{ml}^{-1}$ of melphalan at each change of medium, and the resistance is proposed to be associated with increased levels of glutathione as well as genes involved in cell cycle and DNA repair (Bellamy et al, 1991; Mulcahy et al, 1994; Hazlehurst et al, 2003). U937 vcr was continuously cultured in the presence of $10 \mathrm{ng} \mathrm{ml}^{-1}$ vincristine, and the resistance is proposed to be rubulin associated (Botling et al, 1994). H69AR was alternately fed with drug-free medium and medium containing $0.46 \mu \mathrm{g} \mathrm{ml}^{-1}$ of doxorubicin, and overexpresses MRP1/ABCC1 (Mirski et al, 1987; Cole et al, 1992; Slovak et al, 1993). CEM/ VM-1 was cultured in drug-free medium and could be grown for 3-4 months without loss of resistance against teniposide, which is proposed to be topoisomerase II associated (Danks et al, 1987, 1988; Mao et al, 1999). The primary drug resistance of ACHN is probably multifactorial (Nygren and Larsson, 1991). All cells were grown in culture medium RPMI-1640 supplemented with $10 \%$ heat-inactivated foetal calf serum, $2 \mathrm{~mm}$ glutamine, $100 \mu \mathrm{g} \mathrm{ml}^{-1}$ streptomycin and $100 \mathrm{U} \mathrm{ml}^{-1}$ penicillin (all from Sigma Aldrich Co, St Louis, MO, USA) at $37^{\circ} \mathrm{C}$ in humidified air containing $5 \%$ $\mathrm{CO}_{2}$. The resistant cell lines were tested regularly for maintained resistance to the selected drugs. Growth and morphology of all cell lines were monitored on a weekly basis.

\section{Measurement of drug activity}

A total of 66 anticancer drugs (Table 1), obtained from commercial sources or from NCI, were dissolved according to the manufacturer's instructions and tested in five concentrations, obtained by 10 -fold serial dilution. The investigational alkylating agents $\mathrm{Jl}$ and P2 were kind gifts from Oncopeptides AB (Stockholm, Sweden). The Fluorometric Microculture Cytotoxicity Assay (FMCA), described in detail previously (Larsson et al, 1990), is based on measurement of fluorescence generated from hydrolysis of fluoroscein diacetate (FDA) to fluorescein by cells with intact plasma membranes. Briefly, cells were seeded into microtitre plates (Nunc, Roskilde, Denmark) prepared with drugs and incubated at $37^{\circ} \mathrm{C}$ and $5 \% \mathrm{CO}_{2}$. for $72 \mathrm{~h}$. Then the plates were washed, FDA added, and, after $40 \mathrm{~min}$ of incubation, the fluorescence was measured in a Fluoroscan II (Labsystems Oy, Helsinki, Finland). The fluorescence is proportional to the number of living cells and data are presented as survival index, defined as the fluorescence of experimental wells in percent of control wells with blank values subtracted. The $\mathrm{IC}_{50}$ value for each drug in each cell line was obtained from concentration-response curves constructed in Excel (Microsoft) and GraphPadPrism (GraphPad Software Inc., CA, USA).
Table I Anticancer drugs used in the study

\section{Antimetabolites}

Acivicin, Aminopterin, Aphidicolin, 5-Azacytidine, L-Alanosine, Cladribine Cyclocytidine, Cytarabine, 3-Deazauridine, 2-Azacytidine, Diglycoaldehyde, Fludarabine, 5-Fluorouracil, Ftorafur, Hydroxyurea, 6-Mercaptopurine Methotrexate, PALA, Pentostatin, 6-Thioguanine, Thymidine

\section{Alkylating agents}

Busulfan, Carboplatin, Chlorambucil, Cisplatin, 4-HC, JI, Mechlorethamine, Melphalan, Mitomycin C, P2, Sarcolysine

Topoisomerase l-inhibitors

Camptothecin, SN-38, Topotecan

Topoisomerase Il-inhibitors

Amsacrine, Bisantrene, Daunorubicin, Doxorubicin, Epirubicin, Etoposide, Idarubicin, Mitoxantrone Teniposide

\section{Proteasome inhibitors}

Bortezomib, Lactacystin, MG-132, MG-262

Tubulin active agents

Colchicine, Docetaxel, Maytansine, Paclitaxel, Podophyllotoxin, Vinblastine, Vincristine, Vindesine, Vinorelbine, Estramustine

Others

Aclarubicin, Anguidine, Cycloheximide, Flavoneacetate, Hoechst 33342, MBGB, MIBG, Spirogermanium

PALA = N-phosphonacetyl-L-aspartate; 4-HC = 4-hydroperoxy-cyclophosphamide; MGBG = methylglyoxal-bis (guanylhydrazone); $\quad$ MIBG = meta-iodobenzylguanidine; $\mathrm{SN}-38$ = active metabolite of camptothecin; II and P2, oligopeptide derivatives of melphalan and sarcolysine, respectively.

\section{RNA extraction and reference composition}

Total RNA was extracted from each cell line starting from 10 cells, using Trizol reagent (Invitrogen, Carlsbad, CA, USA) according to the manufacturer's protocol. The purity of the RNA was ensured by measuring the optical density at 260 and $280 \mathrm{~nm}$. The integrity of the RNA was controlled by capillary electrophoresis using a Bioanalyzer 2100 (Agilent Technologies, Palo Alto, CA, USA). Only pure RNA (OD 260/280 >1.8) without any sign of degradation was used in the subsequent experiments. The common reference RNA used in the array experiments was composed of equal aliquots from the cell lines HELA, ACHN, U937-GTB, HTERT-RPE and H69AR.

\section{Array fabrication}

In all, 7458 cDNA clones, included in the Human Sequence Verified Set, were obtained from Research Genetics (Huntsville, $\mathrm{AL}, \mathrm{USA}$ ). A complete list of genes printed on the arrays is available at: http://www.genpat.uu.se/Forskargrupper/wcn/UU/InstrAndProd_section.htm\#prod. Plasmids containing clones were grown in Escherichia coli overnight in 96-well microtitre plates. Plasmid DNA was isolated using the Millipore Plasmid Miniprep 96 Kit (Millipore, Bedford, MA, USA) and clone inserts were amplified using vector-specific primers (Universal Forward 5'CTGCAAGGCGATTAAGTTGGGTAAC- $3^{\prime}$ and Universal Reverse 5'-GTGAGCGGATAACAATTTCACACAGGAAACAGC- $3^{\prime}$ ). The PCR products were purified with the Millipore Multiscreen PCR 96-well plate filtration system (Millipore) and dissolved in $45 \mu \mathrm{l}$ MilliQ-water. The PCR products were dried and re-suspended in MilliQ-water, containing 30\% DMSO, to a final concentration of $0.1 \mathrm{mg} \mathrm{ml}^{-1}$. The PCR products were printed with a Cartesian Prosys 5510A (Cartesian Technologies Inc., Irvine, CA, USA) in duplicates with eight 3B Stealthpins (TeleChem International Inc., Sunnyvale, CA, USA) on GAPSII slides (Corning Life Sciences, 
Acton, MA, USA). The printing temperature was $25^{\circ} \mathrm{C}$ and the relative humidity $65 \%$. The spotted PCR products were crosslinked to the slides at $450 \mathrm{~mJ}$ using a Stratalinker UV 1800 (Stratagene, La Jolla, CA, USA).

\section{Probe preparation, hybridisation, development and image acquisition}

Labelling and detection of cDNA were carried out using the TSA Labelling and Detection Kit (NEN Life Science Products, Boston, MA, USA). The TSA probe labelling, array hybridisation and development were performed as described previously (Karsten et al, 2002). The microarrays were scanned in a GenePix 4000B scanner (Axon Instruments, Union City, CA, USA) at wavelengths 635 and $532 \mathrm{~nm}$ for Cy5 and Cy3 dyes, respectively, using $10-\mu \mathrm{m}$ resolution.

\section{Image processing and normalisation and filtering}

The images were analysed and raw data were extracted, using GenePix Pro software version 5.0. (Axon Instruments). Raw data were normalised using the SMA package (Statistics for Microarray Analysis: http://www.stat.berkeley.edu/users/terry/zarray/Software/ smacode.html). The algorithm used was LOWESS print tip normalisation (Yang et al, 2002). Each cell line was analysed on two separate arrays with the dyes reversed, providing a total of four (genes printed in duplicates on each array) measurements per gene and cell line. Genes with missing values for more than half of the cell lines were removed from the data set. This filter reduced the number of genes from 7458 to 3903 . For genes passing this filtering criteria, an average expression level for each gene and sample was calculated and used in further analysis.

\section{Data analysis}

The drug- and gene-expression databases were integrated and a correlation analysis performed in a custom-made program with similar functions as COMPARE (http://www.nci-sw. com/compare.html). Pearson's correlation coefficients for all drug-drug (log 10 $\left.\mathrm{IC}_{50}\right)$, gene-gene $(\log 2)$ and drug-gene correlations $(\log 10, \log 2)$ were automatically calculated and stored in this database. Differential drug activity and differential gene expression were displayed in delta graphs. The cell line panel mean log $10 \mathrm{IC}_{50}$ or $\log 2$ gene-expression values were determined and subtracted from the $\log 10$ or $\log 2$ values for each cell line to yield the variable defined as delta. Unsupervised hierarchical cluster analysis for cells-genes, cells-drugs and genes-drugs was performed with the CIMminer software (http://discover.nci.nih.Kov/nature2000/tools/ cimmaker.isp) using average linkage clustering with Pearson's correlation coefficient as the measure of similarity. A correlation coefficient above 0.7 or below -0.70 was chosen to extract the genes specifically associated with drug sensitivity and resistance, respectively. This level of Pearson's correlation coefficient corresponds to a significance level of $P<0.05$ for a two-tailed test for 10 observation pairs of the null hypothesis that the correlation is zero.

\section{Identification of molecular pathways}

The genes connected to general chemosensitivity and resistance were analysed using PathwayAssist software to identify signalling pathways (Pathway assist v3.0. (www.ariadnegenomics.com). PathwayAssist is a software for visualisation and exploration of biological pathways, gene regulation networks and proteinprotein interactions. PathwayAssist is supplied with ResNet molecular interaction and pathway database, which contains more than 500000 functional links for more than 50000 proteins, extracted from more than 5000000 Medline abstracts and fulllength articles (ResNet update Q4 2004).

\section{RESULTS}

\section{Analysis of the gene expression and drug activity data sets}

A cDNA microarray analysis was performed to investigate the expression profiles of the 7458 genes in each of the 10 cell lines. Of these genes, 3903 fulfilled the preset quality criteria for subsequent analyses. An example is shown in Figure 1, in which the accurate detection of the ABCC1 transporter in the cell lines is shown. In general, cDNA microarray expression data need to be validated to ensure that the correct gene expression has been measured. In this case, oligonucleotide arrays with a shorter more specific probe has been used to validate $\mathrm{MRPl} / \mathrm{ABCCl}$ expression (correlation coefficient $r>0.9$, data not shown). H69AR showed an increased expression of $\mathrm{MRPl} / \mathrm{ABCCl}$ compared to all other cell lines, which is consistent with previous results, further supporting the validity of the array measurements (Cole et al, 1992). A hierarchical clustering method was then applied to the gene expression in the cell lines (Figure 2). The parental cell lines clustered with their resistant sublines, indicating that no gross alteration in the gene expression profile resulted from the selection of the drug-resistant sublines. Next, correlations were established between the $\log 2$ expression values of each of these 3903 genes and the $\log 10 \mathrm{IC}_{50}$ values obtained for each of the 66 drugs included in the study. Hierarchical clustering of drugs based on these drug-gene correlations resulted in clusters consisting of drugs with similar modes of action (Figure 3). All proteasome inhibitors and topoisomerase I (Topi) inhibitors and most of the antitubulins, topoisomerase II (Top2) inhibitors and alkylating agents formed distinct clusters. Notable exceptions were the tubulin active agents vindesine and estramustine, which did not cluster within their assigned mechanistic group. The antimetabolites clustered more heterogeneously, but closely related drugs with respect to mechanism of action, such as the dihydrofolate reductase inhibitors methotrexate and aminopterin, clustered together. Also, $\mathrm{Jl}$ and P2, oligopeptide derivatives of melphalan and sarcolysine, respectively, did not cluster with their parent compounds. Clustering of drugs based on drug activity alone yielded similar results as the clustering based on the drug-gene correlations (data not shown). An example of a typical drug-gene relationship is shown in Figure 4 Concentration - response curves for doxorubicin

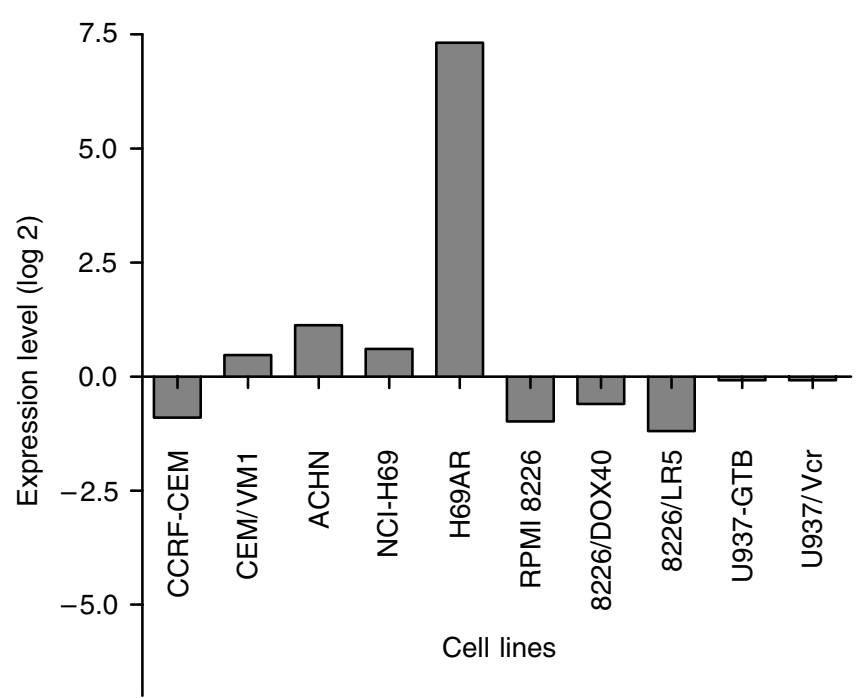

Figure I Differential expression of MRPI/ABCCI in the cell line panel. 


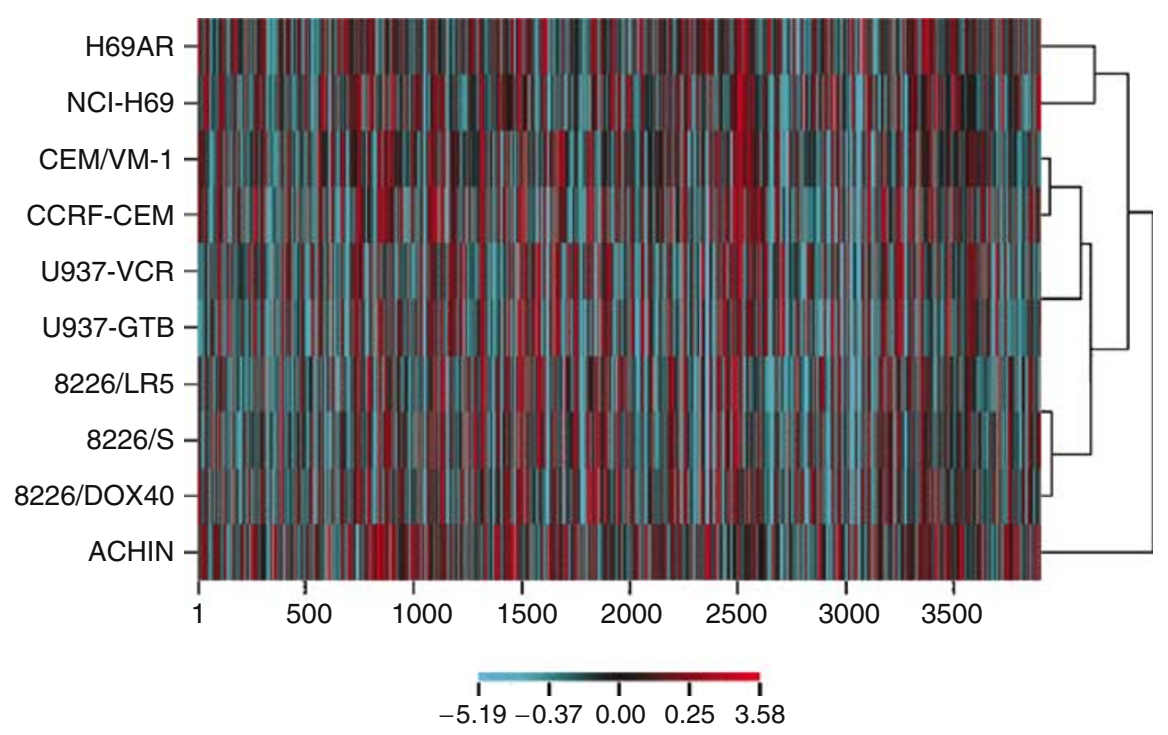

Figure 2 Two-dimensional hierarchical clustering analysis based on similarities in gene expression in the cell lines.
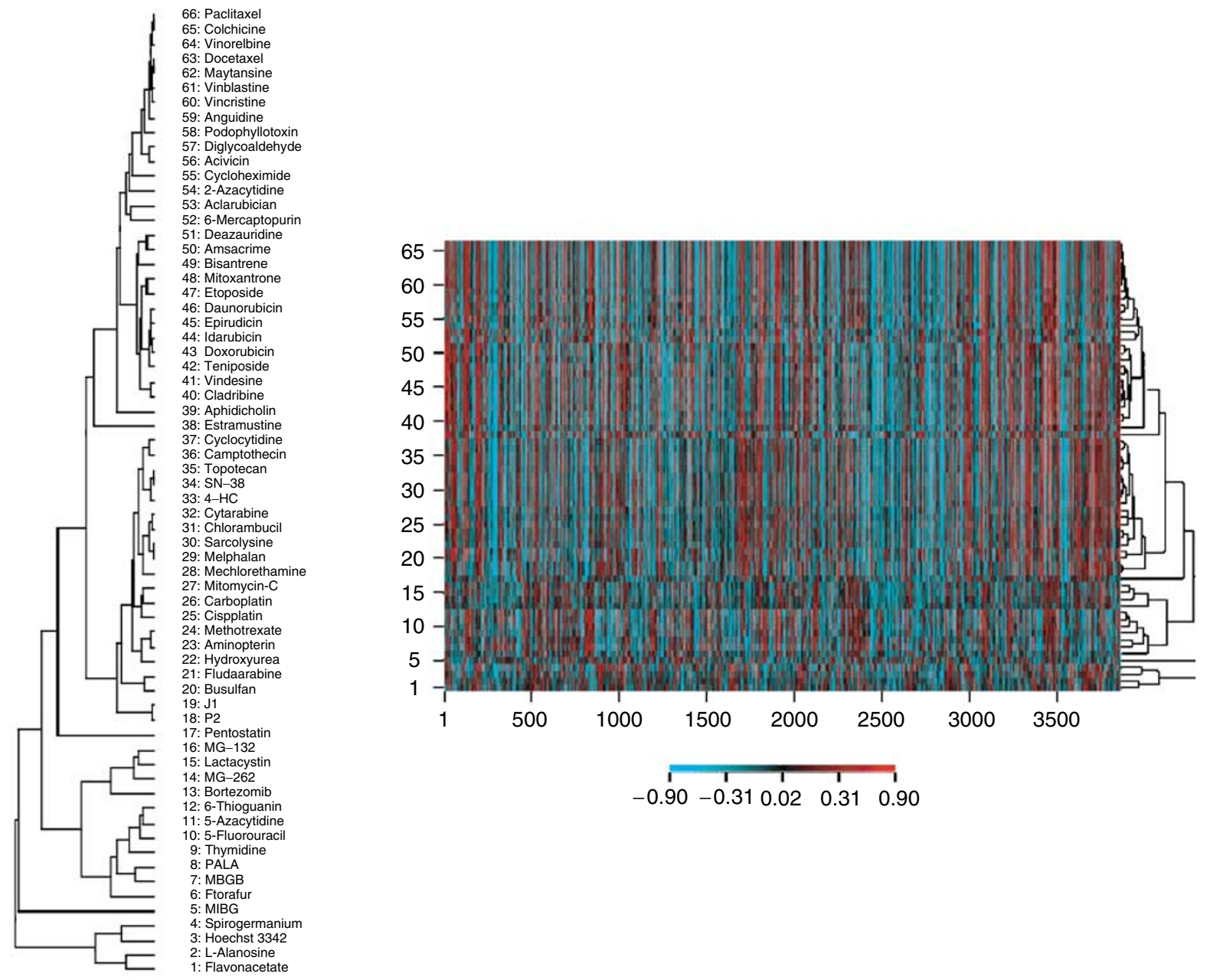

Figure 3 Two-dimensional hierarchical clustering analysis based on drug-gene correlations (Pearsons correlation coefficients) for drug response data $\left(\log 101 C_{50}\right)$ of 66 anticancer drugs and 3903 genes $(\log 2)$ in the 10 cell lines. 
A

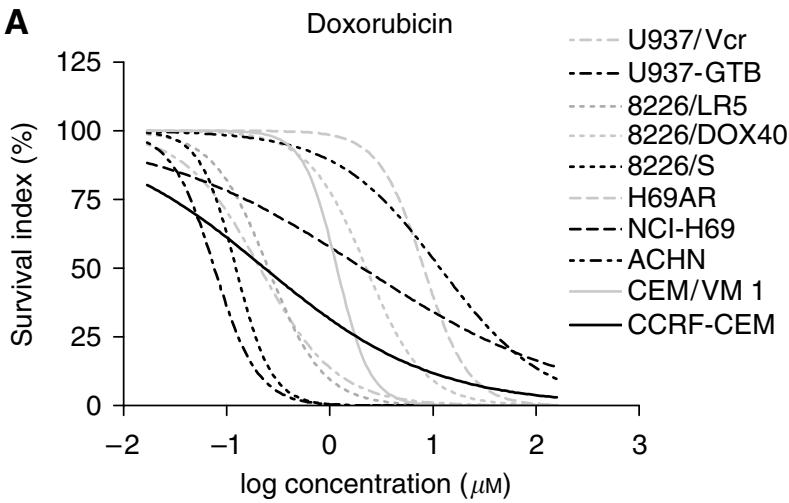

B

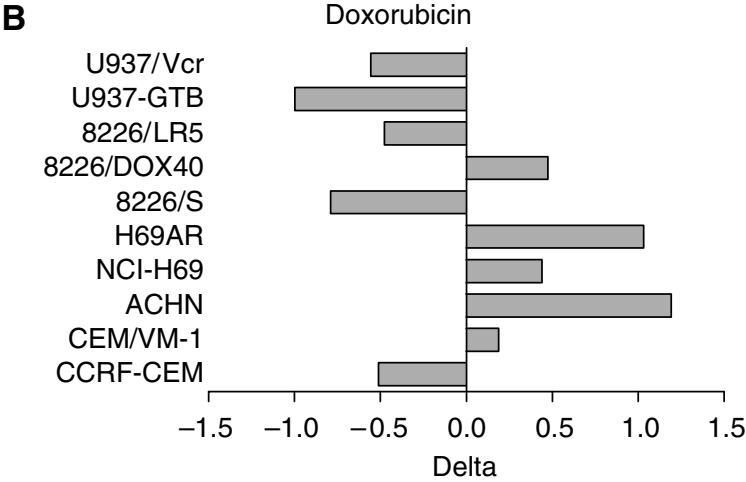

C
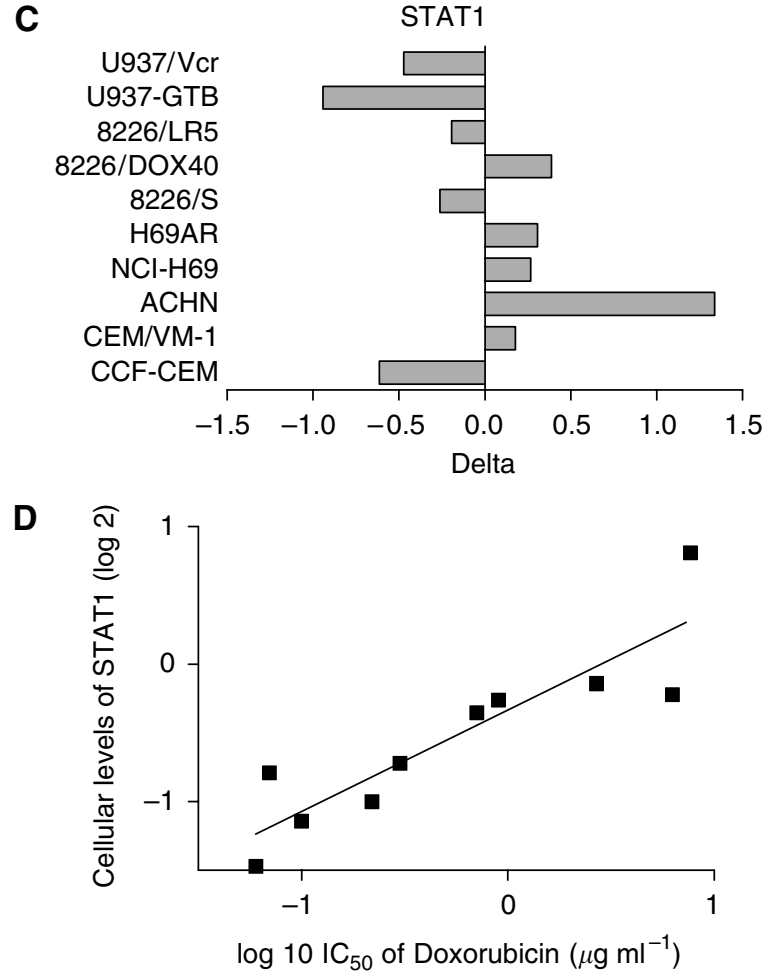

Figure 4 An example of the drug-gene correlations obtained. Concentration-response curves for doxorubicin in the cell line panel (A). Correlation between $\log 2$ expression of STATI with $\log I C_{50}$ of doxorubicin (B). Mean graphs of doxorubicin $(\mathbf{C})$ and STATI (D).

in the cell line panel and delta graphs for differential drug activity and STAT1 gene expression are depicted in panels A-C, respectively. The activity $\left(\log 10 \mathrm{IC}_{50}\right)$ of doxorubicin and the expression of STAT1 $(\log 2)$ in the cell lines were highly correlated (panel $\mathrm{D}, R=0.89$ ). Table 2 displays the 40 genes with the highest positive and negative correlations to doxorubicin.

\section{Identification of signalling pathways associated to drug sensitivity and resistance}

Genes where $R>0.70$. and $<-0.70$ were extracted for each of the 66 drugs (supplementary information online). A correlation coefficient of $>0.70$ or $<-0.70$ in at least 20 of the 66 drugs was set as the criterion for the selection of genes associated to chemosensitivity. This selection identified 122 and 74 genes correlated to general resistance and sensitivity, respectively. Next, Pathway Assist was used in two steps to explore the interactions between the genes on the two lists. In the first step, the ResNet database was searched to establish direct interactions between the genes, and, in the second step, the genes were searched for linkage to cellular processes involving cellular proliferation, cell survival, cell death or apoptosis. The genes selected in this way to form these molecular networks are listed in Tables 3 and 4. The two networks are accessible in supplementary information online as html web files, and the connections are clickable (dots on lines) to access hyperlinks to the Medline references on which the networks are based. Clicking on the nodes provides hyperlinks to several gene and protein databases, including HUGO, OMIM, Locus Link and Swiss-Prot for the particular protein. A simplified version of the network for genes associated with drug resistance is shown in Figure 5. Regarding genes associated to sensitivity, there was a considerable number that could be linked to cell cycle and proliferation regulation rather than apoptosis, including genes such as CDC25A, CCNC, CCND3 and STAT5A (Figure 5A). Notably, for the resistance associated genes, both known proapoptotic and antiapoptotic pathways were detected in the resulting network (Figure 5B). In this molecular network, caspase 3 and 6 and Jun were identified together with survival genes such as RB1, calpastatin, PTK2 and MAPK.1. These gene/pathway maps may provide novel potential molecular targets for therapy. In addition to the genes selected by Pathway Assist, several other potentially relevant genes fulfilled the general resistance and sensitivity criteria including $\mathrm{ABC}$ transporters, drug-inactivating enzymes and protein kinases (for complete general sensitivity and resistance lists, see the supplementary information online).

\section{DISCUSSION}

Gene-drug relationships in large panels of cancer cell lines with different histological origins have been studied previously (Scherf et al, 2000; Dan et al, 2002). In the present study, we studied the gene expression and drug activity in a panel of 10 cell lines representing different mechanisms of anticancer drug resistance. Previous studies have shown that drug activity patterns in this panel can be used to classify anticancer drugs according to mechanism of action (Dhar et al, 1996). Here we showed that this classification also corresponded to identifiable patterns of gene expression and that the genes which correlated to drug sensitivity and resistance seem to be biologically relevant. The geneexpression profiles of the cell lines were similar for cells with the same histological origin and the hierarchical clustering performed based on drug-gene correlations for the drugs in the cell lines yielded clusters of drugs based on their main mechanism of action, with some exceptions. There are several possible reasons for incorrect clustering, and these include experimental variability and incorrect or incomplete assignment of the mechanism of action. Concerning the antimetabolites, the clustering was not clearly linked to known structural or mechanistic features. Given the very diverse mechanistic properties of these drugs, this was not an unexpected finding. Other drugs that deviated from the expected 
Table 2 The genes with highest positive and negative correlations to doxorubicin

\begin{tabular}{|c|c|c|c|}
\hline Symbol & Acc ID & Name & $\boldsymbol{R}$ \\
\hline CTTN & M98343 & Cortactin & 0.96 \\
\hline SLC39AI & BC047288 & Solute carrier family 39 (zinc transporter), member I & 0.93 \\
\hline TTF2 & NM_003594 & Transcription termination factor, RNA polymerase ॥ & 0.93 \\
\hline TPII & ВМ9̄। 3099 & Triosephosphate isomerase I & 0.93 \\
\hline DDAHI & NM_012137 & Dimethylarginine dimethylaminohydrolase | & 0.92 \\
\hline EXTLI & NM_004455 & Exostoses (multiple)-like | & 0.92 \\
\hline GNAII & $\mathrm{BC} 063426$ & Guanine nucleotide binding protein (G protein), alpha II & 0.92 \\
\hline MAPKII & BC027933 & Mitogen-activated protein kinase II & 0.92 \\
\hline SURB7 & NM_004264 & SRB7 suppressor of RNA polymerase B homolog (yeast) & 0.91 \\
\hline HLA-DOA & NM_002II9 & Major histocompatibility complex, class II, DO alpha & 0.90 \\
\hline STATI & NM_007315 & Signal transducer and activator of transcription I, 9| kDa & 0.89 \\
\hline AGRN & $A B|\overline{9}| 264$ & Agrin & 0.89 \\
\hline PTTGIIP & AK095586 & Pituitary tumour-transforming I interacting protein & 0.89 \\
\hline FXYDI & AKI24802 & FXYD domain containing ion transport regulator I & 0.88 \\
\hline DRPLA & BC05।795 & Dentatorubral-pallidoluysian atrophy & 0.88 \\
\hline TULP3 & NM_003324 & Tubby like protein 3 & 0.88 \\
\hline BCARI & AKI 24526 & Breast cancer anti-oestrogen resistance | & 0.88 \\
\hline SPAG9 & AF327452 & Sperm associated antigen 9 & 0.87 \\
\hline $\mathrm{ABCB} 6$ & BC043423 & ATP-binding cassette, subfamily B (MDR/TAP), member 6 & 0.87 \\
\hline CAST & NM_I73060 & Calpastatin & 0.87 \\
\hline BNIP2 & AKI 25533 & BCL2/adenovirus EIB 19 kDa interacting protein 2 & -0.97 \\
\hline GCAT & AKI23190 & Glycine C-acetyltransferase & -0.92 \\
\hline TIMMIO & $\mathrm{BQ} 01 \mid 318$ & Translocase of inner mitochondrial membrane 10 homolog (yeast) & -0.91 \\
\hline RNUTI & BG42I 329 & RNA, U transporter I & -0.90 \\
\hline ASCC3 & AL834463 & DJ467N I I.I protein & -0.90 \\
\hline GAS7 & NM_201433 & Growth arrest-specific 7 & -0.88 \\
\hline COROIA & AKI 23401 & Coronin, actin-binding protein, IA & -0.88 \\
\hline LCP2 & NM_005565 & Lymphocyte cytosolic protein 2 & -0.88 \\
\hline WAS & $\mathrm{BM} 455138$ & Wiskott-Aldrich syndrome & -0.88 \\
\hline EBP & BE253850 & Emopamil-binding protein & -0.88 \\
\hline PSD4 & BC073।5। & Pleckstrin and Sec7 domain containing 4 & -0.87 \\
\hline KIAAI 545 & AB046765 & KIAAI 545 protein & -0.87 \\
\hline $\mathrm{IDH} 3 \mathrm{~A}$ & AKI23316 & Isocitrate dehydrogenase $3(\mathrm{NAD}+)$ alpha & -0.87 \\
\hline NIPBL & AJ627032 & Nipped-B homolog (Drosophila) & -0.86 \\
\hline POLQ & NM_006596 & Polymerase (DNA directed), theta & -0.86 \\
\hline Cl5orf22 & AK075529 & Chromosome 15 open reading frame 22 & -0.85 \\
\hline RAC2 & AK096924 & Ras-related $C 3$ botulinum toxin substrate 2 & -0.85 \\
\hline PHF2 & NM_005392 & PHD finger protein 2 & -0.85 \\
\hline TPBG & NM_006670 & Trophoblast glycoprotein & -0.85 \\
\hline ARHGDIB & AKI $\overline{2} 5625$ & Rho GDP dissociation inhibitor (GDI) beta & -0.84 \\
\hline
\end{tabular}

clustering were vindesine, estramustine, $\mathrm{J} 1$ and $\mathrm{P} 2$. As an example, $\mathrm{Jl}$ and P2, oligopeptide derivatives of melphalan and sarcolysine, respectively, clustered together, but differently from their parent compounds. Jl is currently undergoing clinical development, and recent studies have indicated other mechanisms of cell death additional to the death caused by DNA alkylation (Gullbo et al, 2003). The overall results indicate that the panel of 10 tumour cell lines was able to reasonably well classify drugs with respect to the mechanism of action.

The mechanistic pathways identified with PathwayAssist associated to general drug resistance paradoxically included a substantial number of both proapoptotic and antiapoptotic genes. The proapoptotic genes caspase 3 and 6 (CASP3, 6) and Jun were identified together with survival genes such as retinoblastoma 1 (RBI), calpastatin (CAST), focal adhesion kinase/protein tyrosine kinase 2 (FAK/PTK2) and mitogen-activated protein kinase 1 (MAPK1). A parallel upregulation of pro- and antiapoptotic genes in malignant tumours has been observed in several microarray studies comparing tumour cells and normal tissue (Rhodes et al, 2004; www.oncomine.com), indicating that the balance between upregulated pro- and antiapoptotic genes may be critical for tumour cell survival. To affect this balance by small molecules may thus be a potential therapeutic strategy. The expression of signal transducer and activator of transcription 1 (STATl) was also observed to be highly correlated to resistance, particularly for the
Top2 inhibitors (data not shown). Although activation of STATl in some cell systems has been shown to be proapoptotic (Calo et al, 2003), a recent observation has indicated a role for STATl in mediating radiation resistance (Khodarev et al, 2004). Recently, a correlation between STATl expression and cisplatin resistance in cell lines derived from patients with ovarian carcinoma was also reported (Roberts et al, 2005), and inhibitors of the STATl pathway have been shown to induce apoptosis in leukaemic cells from patients (Martinez-Lostao et al, 2005). The pathway analysis showed that STATl is positively influenced by MAPK1 and FAK, two of the most highly connected resistance-associated genes, both of which have been reported to inhibit apoptosis (Shimada et al, 2002; Kurenova et al, 2004). Notably, STATl expression has been reported higher in tumour compared with corresponding normal tissue for a wide range of tumour types (www.oncomine.com). The STATl pathway may thus provide a potentially interesting drug target for reversal of drug resistance.

The genes correlated to drug sensitivity had diverse functions, but a considerable number were found to be related to cell cycle and proliferation rather than to apoptosis, for example, cell division cycle 25A (CDC25A) and signal transducer of activator of transcription 5A (STAT5A). This is in accordance with the general notion of a correlation between high proliferation and increased anticancer drug sensitivity (Valeriote and van Putten, 1975; Kaaijk et al, 2003). 
Table 3 Genes associated with drug resistance selected by PathwayAssist

\begin{tabular}{|c|c|}
\hline Symbol & Name \\
\hline AGRN & Agrin \\
\hline APP & $\begin{array}{l}\text { Amyloid beta (A4) precursor protein (protease nexin-ll, } \\
\text { Alzheimer's disease) }\end{array}$ \\
\hline BACE2 & Beta-site APP-cleaving enzyme 2 \\
\hline BAG3 & Bcl2-associated athanogene 3 \\
\hline BASPI & Brain abundant, membrane-attached signal protein I \\
\hline BCARI & Breast cancer antioestrogen resistance | \\
\hline BMPRIA & Bone morphogenetic protein receptor, type IA \\
\hline CASP3 & Caspase 3 , apoptosis-related cysteine protease \\
\hline CASP6 & Caspase 6, apoptosis-related cysteine protease \\
\hline CAST & Calpastatin \\
\hline CD9 & CD9 antigen (p24) \\
\hline CKAP4 & Cytoskeleton-associated protein 4 \\
\hline CREBBP & CREB-binding protein \\
\hline CSPG2 & Chondroitin sulphate proteoglycan 2 (versican) \\
\hline CTTN & Cortactin \\
\hline DAGI & Dystroglycan I (dystrophin-associated glycoprotein I) \\
\hline DDAHI & Dimethylarginine dimethylaminohydrolase | \\
\hline DRPLA & Dentatorubral-pallidoluysian atrophy (atrophin-1) \\
\hline EPHA2 & EphA2 \\
\hline FXYDI & $\begin{array}{l}\text { FXYD domain containing ion transport regulator I } \\
\text { (phospholemman) }\end{array}$ \\
\hline HIFIA & $\begin{array}{l}\text { Hypoxia-inducible factor I, alpha subunit (basic helix-loop- } \\
\text { helix transcription factor) }\end{array}$ \\
\hline IGSF4 & Immunoglobulin superfamily, member 4 \\
\hline ITGAV & $\begin{array}{l}\text { Integrin, alpha } \vee \text { (vitronectin receptor, alpha polypeptide, } \\
\text { antigen CD5I) }\end{array}$ \\
\hline ITPR3 & Inositol 1,4,5-triphosphate receptor, type 3 \\
\hline ITSNI & Intersectin I (SH3 domain protein) \\
\hline JUN & Jun oncogene \\
\hline LTBPI & Latent transforming growth factor beta binding protein I \\
\hline MAFG & $\begin{array}{l}\text { V-maf musculoaponeurotic fibrosarcoma oncogene homologue } \\
\mathrm{G} \text { (avian) }\end{array}$ \\
\hline MAP4K3 & Mitogen-activated protein kinase kinase kinase kinase 3 \\
\hline MAPKI & Mitogen activated protein kinase | \\
\hline MAPKII & Mitogen-activated protein kinase II \\
\hline MDK & Midkine (neurite growth-promoting factor 2) \\
\hline NBLI & Neuroblastoma, suppression of tumorigenicity I \\
\hline NEFL & Neurofilament, light polypeptide $68 \mathrm{kDa}$ \\
\hline PAWR & PRKC, apoptosis, WTI, regulator \\
\hline PEAI5 & Phosphoprotein enriched in astrocytes 15 \\
\hline PLXNBI & Plexin $\mathrm{BI}$ \\
\hline POR & P450 (cytochrome) oxidoreductase \\
\hline PTK2 & PTK2 protein tyrosine kinase 2 \\
\hline PTPNI3 & Protein tyrosine phosphatase, nonreceptor type 13 \\
\hline PXN & Paxillin \\
\hline RBI & Retinoblastoma I \\
\hline RDX & Radixin \\
\hline RIPK2 & Receptor-interacting serine-threonine kinase 2 \\
\hline SIOOAIO & $\begin{array}{l}\text { SI } 00 \text { calcium-binding protein AIO (annexin II ligand, calpactin I, } \\
\text { light polypeptide }(p \mid l) \text { ) }\end{array}$ \\
\hline SERPINHI & $\begin{array}{l}\text { Serine (or cysteine) proteinase inhibitor, clade } \mathrm{H} \text { (heat shock } \\
\text { protein } 47 \text { ), member I (collagen-binding protein I) }\end{array}$ \\
\hline STATI & Signal transducer and activator of transcription I \\
\hline TPII & Triosephosphate isomerase | \\
\hline TRAI & Tumour rejection antigen (gp96) । \\
\hline TUBB & Tubulin, beta polypeptide \\
\hline TULP3 & Tubby like protein 3 \\
\hline
\end{tabular}

The listed genes were selected by the PathwayAssist software as described in the Results section. An interactive graphical version is available in the supplementary information online.

Some limitations of the study should be discussed. First, cell lines removed from their in vivo environment and selected for growth in culture differ from tumour cells in patients. Therefore, the relevance of the genes and mechanistic pathways needs to be studied in additional settings, such as primary cultures of tumour cells from patients. Second, the drug activity database was generated using a single assay end point, that is, short-term
Table 4 Genes associated with drug sensitivity selected by PathwayAssist

\begin{tabular}{|c|c|}
\hline Symbol & Name \\
\hline ARHGDIB & Rho GDP dissociation inhibitor (GDI) beta \\
\hline BCCIP & BRCA2 and CDKNIA interacting protein \\
\hline CCNC & Cyclin C \\
\hline CCND3 & Cyclin D3 \\
\hline CD37 & CD37 antigen \\
\hline CD4 & CD4 antigen \\
\hline $\mathrm{CD} \times 2$ & Caudal type homeo box transcription factor 2 \\
\hline CKLF & Chemokine-like factor \\
\hline COROIA & Coronin, actin-binding protein, IA \\
\hline DOCK2 & Dedicator of cytokinesis 2 \\
\hline GAS7 & Growth arrest-specific 7 \\
\hline GNAI5 & $\begin{array}{l}\text { Guanine nucleotide-binding protein (G protein), alpha I5 (Gq } \\
\text { class) }\end{array}$ \\
\hline $\mathrm{HDACl}$ & Histone deacetylase I \\
\hline $\mathrm{IDH} 3 \mathrm{~A}$ & Isocitrate dehydrogenase $3(\mathrm{NAD}+)$ alpha \\
\hline IL2RG & $\begin{array}{l}\text { Interleukin } 2 \text { receptor, gamma (severe combined } \\
\text { immunodeficiency) }\end{array}$ \\
\hline IMPDH2 & IMP (inosine monophosphate) dehydrogenase 2 \\
\hline INPP5D & Inositol polyphosphate-5-phosphatase D \\
\hline LCPI & Lymphocyte cytosolic protein I (L-plastin) \\
\hline LCP2 & $\begin{array}{l}\text { Lymphocyte cytosolic protein } 2 \text { ( } \mathrm{SH} 2 \text { domain containing } \\
\text { leukocyte protein of } 76 \mathrm{kDa})\end{array}$ \\
\hline MAP4KI & Mitogen-activated protein kinase kinase kinase kinase I \\
\hline MCM5 & $\begin{array}{l}\text { MCM5 minichromosome maintenance deficient } 5 \text {, cell division } \\
\text { cycle } 46 \text { (S. cerevisiae) }\end{array}$ \\
\hline MYB & V-myb myeloblastosis viral oncogene homologue (avian) \\
\hline MYCBP2 & MYC binding protein 2 \\
\hline NCF4 & Neutrophil cytosolic factor 4, $40 \mathrm{kDa}$ \\
\hline NUDC & Nuclear distribution gene $\mathrm{C}$ homolog (A. nidulans) \\
\hline PENK & Proenkephalin \\
\hline PPIH & Peptidyl prolyl isomerase $\mathrm{H}$ (cyclophilin $\mathrm{H}$ ) \\
\hline RAC2 & $\begin{array}{l}\text { Ras-related C3 botulinum toxin substrate } 2 \text { (rho family, small } \\
\text { GTP-binding protein Rac2) }\end{array}$ \\
\hline SLC25A5 & $\begin{array}{l}\text { Solute carrier family } 25 \text { (mitochondrial carrier; adenine } \\
\text { nucleotide translocator), member } 5\end{array}$ \\
\hline SLC7A5 & $\begin{array}{l}\text { Solute carrier family } 7 \text { (cationic amino-acid transporter, y+ } \\
\text { system), member } 5\end{array}$ \\
\hline STAT5A & Signal transducer and activator of transcription $5 \mathrm{~A}$ \\
\hline TFR2 & Transferrin receptor 2 \\
\hline TPBG & Trophoblast glycoprotein \\
\hline WAS & Wiskott-Aldrich syndrome (eczema-thrombocytopenia) \\
\hline
\end{tabular}

The listed genes were selected by the PathwayAssist software as described in the Results section. An interactive graphical version is available in the supplementary information online.

growth inhibition and cytotoxicity. Drugs may induce concentration-dependent effects on different targets leading to different modes of cell death, including apoptosis, necrosis and cell senescence (Blagosklonny, 2004). Multiparameter assays using high-content screening may provide a substantial increase in the information on drug activity and mode of cell death (Lövborg et al 2004), and such studies are underway. Third, only a part of all human genes were represented on the arrays used. Also, the genedrug relationships described represent only a small fraction of relationships thought to be relevant to chemotherapy, and many are probably hidden by the arbitrary and rough cutoff criteria that need to be applied for selection of the information, among all the available microarray data, considered to be relevant. Fourth, with respect to the data exploration, the quality of the data obtained is dependent on the information and algorithms in the software used, meaning that these data should only be used for generation of hypotheses that need further and direct confirmation. Finally, although this exploitation of array data using powerful software can provide a basis for identification of new drug targets, it should be emphasised that the relationships observed are correlative, not 


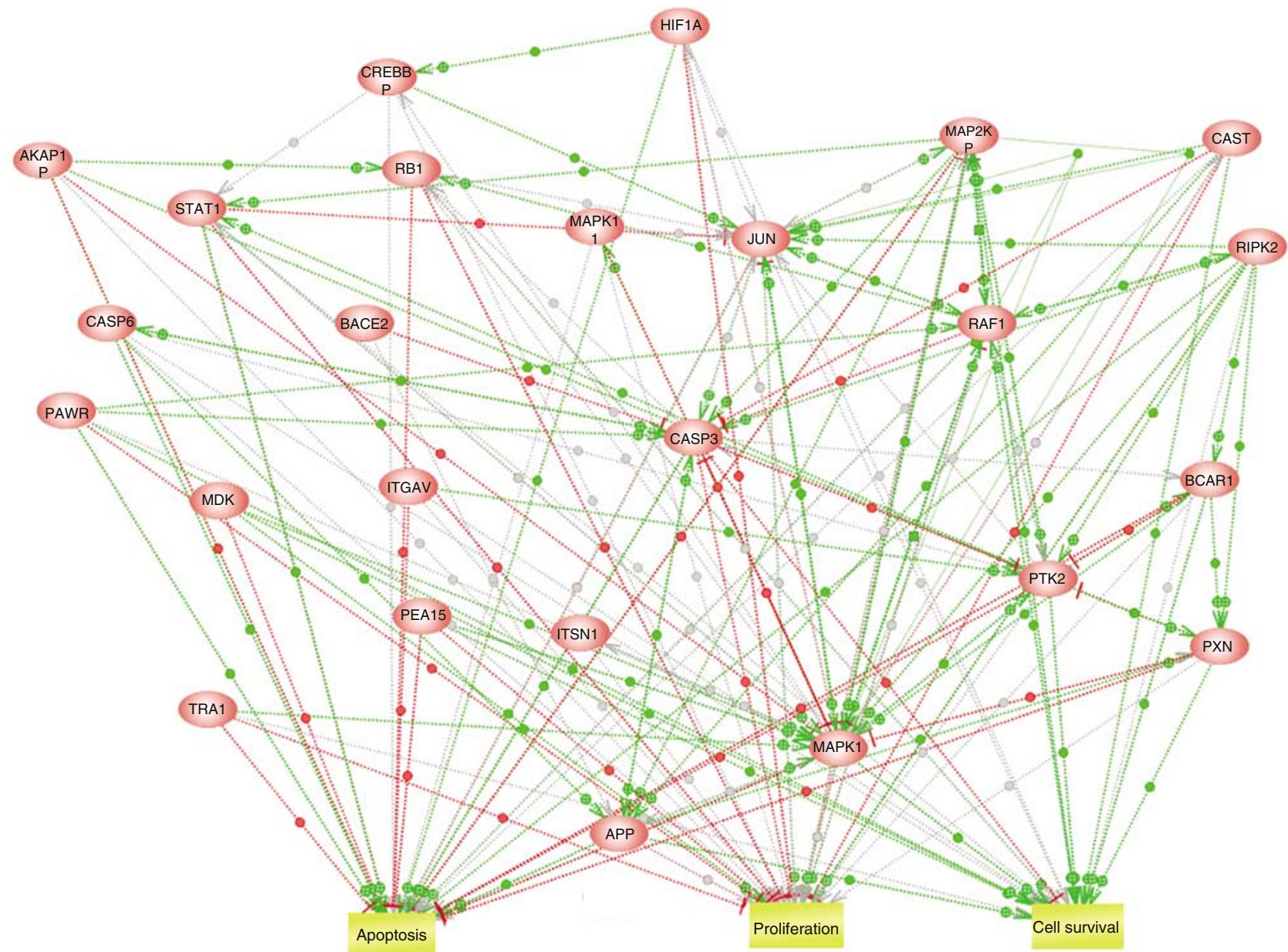

Figure 5 Analysis of molecular interactions using PathwayAssist. A simplified network for genes associated with resistance is shown. Green lines indicate positive effects, red lines indicate negative effects and grey lines interactions with unknown effect. Complete interactive graphical versions of the networks associated with sensitivity and resistance are accessible in supplementary information online and the connections are clickable (dots on lines) to access hyperlinks to the Medline references on which the networks are based. Clicking on the nodes provides hyperlinks to several gene and protein databases including HUGO, Locus Link and Swiss-Prot for the particular protein.

causal, and that these correlations must be further experimentally tested and validated.

In comparison to previous similar studies (Scherf et al, 2000; Dan et al, 2002), we identified other chemosensitivity genes. This might be explained by several limiting factors as discussed above, and include differences in cell types, arrays, drugs and assays used. Even when different arrays were used to study the same samples, the gene-drug relationships were shown to differ (Scherf et al, 2000; Staunton et al, 2001). Furthermore, in the present study, the correlation coefficients for the drug-gene correlations were in general higher than in the previous studies. This might partly be explained by the inclusion of cell lines selected for drug resistance. The selection of drug resistance may impose a larger range of gene expression across samples, leading to higher drug-gene correlation coefficients. This would also potentially increase the possibility of identifying genes specifically associated with drug resistance. An advantage of using parental and drug-resistant cell lines is that the selecting agent and genes specifically involved in resistance to that particular drug could be isolated. However, it should be noted that the ability to cluster drugs based on druggene correlations is not limited to drug classes used for drug resistance selection. Indeed, in the present paper, both the proteasome inhibitors and Top I inhibitors could be distinguished as distinct clusters, although no resistant cell lines representative of these drug classes were included in the panel. Extending the panel with sublines resistant to mechanistically different drugs may nevertheless improve the possibility of identifying genes involved in drug resistance by further increasing the range of relevant gene expression. We are currently introducing cell lines resistant to novel target-specific drugs such as proteasome and tyrosine kinase inhibitors.

In the present study, we employed a molecular pathway analysis tool, Pathway Assist (www.ariadnegenomics.com), for the analysis of obtained drug-gene correlations. This procedure allowed quick and efficient generation of biologically meaningful and literaturevalidated relationships between the genes retrieved. PathwayAssist contains the ResNet database in which more than 500000 events are recorded and any established pathway can be updated online by automated mining of Medline using a built-in Natural Language Processing algorithm (www.ariadnegenomics.com). Performing such pathway analysis manually would have been extremely time consuming and laborious. Automated data-mining tools for pathway analysis will therefore be increasingly important in light of the exploding information content on molecular pathway networks.

In conclusion, integration of gene expression and drug activity data sets for tumour cell line panels provide relationships between individual gene and drug activity profiles that makes it possible to identify drug mechanisms of action that can be traced down to gene level. By also applying powerful software for recognition of 
cell signalling pathways, the current approach might accelerate the drug discovery and evaluation process and provide novel markers and drug targets for the chemotherapy of cancer. The current approach is suitable for characterisation of new drugs both with respect to the mechanism of action and identification of genes involved in drug sensitivity and resistance.

\section{ACKNOWLEDGEMENTS}

We are grateful for all the work with microarray printing performed by Niclas Olsson at the Uppsala Expression Array

\section{REFERENCES}

Bellamy WT, Dalton WS, Gleason MC, Grogan TM, Trent JM (1991) Development and characterization of a melphalan-resistant human multiple myeloma cell line. Cancer Res 51: 995-1002

Blagosklonny MV (2004) Prospective strategies to enforce selectively cell death in cancer cells. Oncogene 23: 2967-2975

Botling J, Liminga G, Larsson R, Nygren P, Nilsson K (1994) Development of vincristine resistance and increased sensitivity to cyclosporin A and verapamil in the human U-937 lymphoma cell line without overexpression of the 170-kDa P-glycoprotein. Int J Cancer 58: 269-274

Boyd MR, Paull KD (1995) Some practical considerations and applications of the National Cancer Institute in vitro anticancer drug discovery screen. Drug Dev Res 34: 91 - 109

Calo V, Migliavacca M, Bazan V, Macaluso M, Buscemi M, Gebbia N, Russo A (2003) STAT proteins: from normal control of cellular events to tumorigenesis. J Cell Physioll 91: 157-168

Cole SP, Bhardwaj G, Gerlach JH, Mackie JE, Grant CE, Almquist KC, Stewart AJ, Kurz EU, Duncan AM, Deeley RG (1992) Overexpression of a transporter gene in a multidrug-resistant human lung cancer cell line. Science 258: $1650-1654$

Dalton WS, Durie BG, Alberts DS, Gerlach JH, Cress AE (1986) Characterization of a new drug-resistant human myeloma cell line that expresses P-glycoprotein. Cancer Res 46: 5125-5130

Dan S, Tsunoda T, Kitahara O, Yanagawa R, Zembutsu H, Katagiri T, Yamazaki K, Nakamura Y, Yamori T (2002) An integrated database of chemosensitivity to 55 anticancer drugs and gene expression profiles of 39 human cancer cell lines. Cancer Res 62: 1139-1147

Danks MK, Schmidt CA, Cirtain MC, Suttle DP, Beck WT (1988) Altered catalytic activity of and DNA cleavage by DNA topoisomerase II from human leukemic cells selected for resistance to VM-26. Biochemistry 27: $8861-8869$

Danks MK, Yalowich JC, Beck WT (1987) Atypical multiple drug resistance in a human leukemic cell line selected for resistance to teniposide (VM26). Cancer Res 47: 1297-1301

Dhar S, Nygren P, Csoka K, Botling J, Nilsson K, Larsson R (1996) Anticancer drug characterisation using a human cell line panel representing defined types of drug resistance. Br J Cancer 74: 888-896

Gullbo J, Dhar S, Luthman K, Ehrsson H, Lewensohn R, Nygren P, Larsson $\mathrm{R}$ (2003) Antitumor activity of the alkylating oligopeptides J1 (L-melphalanyl- $p$-L-fluorophenylalanine ethyl ester) and P2 (L-prolyl$m$-L-sarcolysyl- $p$-L-fluorophenylalanine ethyl ester): comparison with melphalan. Anticancer Drugs 14: 617-624

Hazlehurst LA, Enkemann SA, Beam CA, Argilagos RF, Painter J, Shain KH, Saporta S, Boulware D, Moscinski L, Alsina M, Dalton WS (2003) Genotypic and phenotypic comparisons of de novo and acquired melphalan resistance in an isogenic multiple myeloma cell line model. Cancer Res 63: 7900-7906

Kaaijk P, Kaspers GJ, Van Wering ER, Broekema GJ, Loonen AH, Hahlen K, Schmiegelow K, Janka-Schaub GE, Henze G, Creutzig U, Veerman AJ (2003) Cell proliferation is related to in vitro drug resistance in childhood acute leukaemia. Br J Cancer 88: 775-781

Karsten SL, Van Deerlin VM, Sabatti C, Gill LH, Geschwind DH (2002) An evaluation of tyramide signal amplification and archived fixed and frozen tissue in microarray gene expression analysis. Nucleic Acids Res 30: E4

Khodarev NN, Beckett M, Labay E, Darga T, Roizman B, Weichselbaum RR (2004) STAT1 is overexpressed in tumors selected for radioresistance
Platform, Uppsala, Sweden. The skilful technical assistance of Christina Leek and Lena Lenhammar is gratefully acknowledged. This study was supported by the Swedish Cancer Society, the Swedish Research Council, the Lions Cancer Research Fund, Beijer foundation. Wallenberg Consortium North, Marcus Borgström Foundation, Swedish Society for Medical Research, Göran Gustafsson Foundation, Carl Tryggers Foundation, Stockholm Cancer Society and Swedish Knowledge Foundation.

Supplementary Information accompanies the paper on British Journal of Cancer website (http://www.nature.com/bjc).

and confers protection from radiation in transduced sensitive cells. Proc Natl Acad Sci USA 101: 1714-1719

Kurenova E, Xu LH, Yang X, Baldwin Jr AS, Craven RJ, Hanks SK, Liu ZG, Cance WG (2004) Focal adhesion kinase suppresses apoptosis by binding to the death domain of receptor-interacting protein. Mol Cell Biol 24: $4361-4371$

Larsson R, Nygren P, Ekberg M, Slater L (1990) Chemotherapeutic drug sensitivity testing of human leukemia cells in vitro using a semiautomated fluorometric assay. Leukemia 4: 567-571

Lövborg H, Nygren P, Larsson R (2004) Multiparametric evaluation of apoptosis: effects of standard cytotoxic agents and the cyanoguanidine CHS 828. Mol Cancer Ther 3: 521-526

Mao Y, Yu C, Hsieh TS, Nitiss JL, Liu AA, Wang H, Liu LF (1999) Mutations of human topoisomerase II alpha affecting multidrug resistance and sensitivity. Biochemistry 38: $10793-10800$

Marie JP (2001) Drug resistance in hematologic malignancies. Curr Opin Oncol 13: $463-469$

Martinez-Lostao L, Brioners J, Forné I, Martinez-Gallo M, Ferrer B, Sierra J, Rodrigues-Sanches J, Juarez C (2005) Role of the STAT1 pathway in apoptosis by fludarabine and JAK kinase inhibitors in B-cell chronic lymphocytic leukemia. Leukemia Lymphoma 46: $435-442$

Mirski SE, Gerlach JH, Cole SP (1987) Multidrug resistance in a human small cell lung cancer cell line selected in adriamycin. Cancer Res 47: 2594-2598

Mulcahy RT, Bailey HH, Gipp JJ (1994) Up-regulation of gammaglutamylcysteine synthetase activity in melphalan-resistant human multiple myeloma cells expressing increased glutathione levels. Cancer Chemother Pharmacol 34: 67-71

Nygren P (2001) What is cancer chemotherapy? Ada Oncol 40: $166-174$

Nygren P, Larsson R (1991) Differential in vitro sensitivity of human tumor and normal cells to chemotherapeutic agents and resistance modulators. Int J Cancer 48: 598-604

Paull KD, Shoemaker RH, Hodes L, Monks A, Scudiero DA, Rubinstein L, Plowman J, Boyd MR (1989) Display and analysis of patterns of differential activity of drugs against human tumor cell lines: development of mean graph and COMPARE algorithm. J Natl Cancer Inst 81: $1088-1092$

Pommier Y, Sordet O, Antony S, Hayward RL, Kohn KW (2004) Apoptosis defects and chemotherapy resistance: molecular interaction maps and networks. Oncogene 23: $2934-2949$

Rhodes DR, Yu J, Shanker K, Deshpande N, Varambally R, Ghosh D, Barrette T, Pandey A, Chinnaiyan AM (2004) Large-scale meta-analysis of cancer microarray data identifies common transcriptional profiles of neoplastic transformation and progression. Proc Natl Acad Sci USA 101: 9309-9314

Roberts D, Schick J, Conway S, Biade S, Laub PB, Stevenson JP, Hamilton TC, O’Dwyer PJ, Johnson SW (2005) Identification of genes associated with platinum drug sensitivity and resistance in human ovarian cancer cells. Br J Cancer 92: 1149-1158

Scherf U, Ross DT, Waltham M, Smith LH, Lee JK, Tanabe L, Kohn KW, Reinhold WC, Myers TG, Andrews DT, Scudiero DA, Eisen MB, Sausville EA, Pommier Y, Botstein D, Brown PO, Weinstein JN (2000) A gene expression database for the molecular pharmacology of cancer. Nat Genet 24: $236-244$ 
Shimada K, Nakamura M, Ishida E, Kishi M, Yonehara S, Konishi N (2002) Contributions of mitogen-activated protein kinase and nuclear factor kappa B to $\mathrm{N}$-(4-hydroxyphenyl)retinamide-induced apoptosis in prostate cancer cells. Mol Carcinogen 35: 127-137

Slovak ML, Ho JP, Bhardwaj G, Kurz EU, Deeley RG, Cole SP (1993) Localization of a novel multidrug resistance-associated gene in the HT1080/DR4 and H69AR human tumor cell lines. Cancer Res 53: $3221-3225$

Staunton JE, Slonim DK, Coller HA, Tamayo P, Angelo MJ, Park J, Scherf U, Lee JK, Reinhold WO, Weinstein JN, Mesirov JP, Lander ES, Golub TR (2001) Chemosensitivity prediction by transcriptional profiling. Proc Natl Acad Sci USA 98: 10787-10792

Valeriote F, van Putten L (1975) Proliferation-dependent cytotoxicity of anticancer agents: a review. Cancer Res 35: 2619-2630
Weinstein JN, Kohn KW, Grever MR, Viswanadhan VN, Rubinstein LV, Monks AP, Scudiero DA, Welch L, Koutsoukos AD, Chiausa AJ, Paull KD (1992) Neural computing in cancer drug development: predicting mechanism of action. Science 258: 447-451

Weinstein JN, Myers TG, O'Connor PM, Friend SH, Fornace Jr AJ, Kohn KW, Fojo T, Bates SE, Rubinstein LV, Anderson NL, Buolamwini JK, van Osdol WW, Monks AP, Scudiero DA, Sausville EA, Zaharevitz DW, Bunow B, Viswanadhan VN, Johnson GS, Wittes RE, Paull KD (1997) An information-intensive approach to the molecular pharmacology of cancer. Science 275: $343-349$

Yang YH, Dudoit S, Luu P, Lin DM, Peng V, Ngai J, Speed TP (2002) Normalization for cDNA microarray data: a robust composite method addressing single and multiple slide systematic variation. Nucleic Acids Res 30: el5 